\title{
Construção das identidades de gênero na infância: os discursos dos brinquedos e brincadeiras $^{1}$
}

\section{Construction of gender identities in childhood: the discourses of toys and play}

\section{Construcción de identidades de género en la infancia: los discursos de los juguetes y el juego}

\author{
iD (9) karine Natalie Barra Godoy \\ Universidade Federal de Juiz de Fora, Juiz de Fora, Minas Gerais, Brasil \\ karine.godoy@hotmail.com
}

iD Ludmila Mourão

Universidade Federal de Juiz de Fora, Juiz de Fora, Minas Gerais, Brasil mouraoln@gmail.com

iD Ayra Lovisi Oliveira

Universidade Federal de Juiz de Fora, Juiz de Fora, Minas Gerais, Brasil ayralovisi@yahoo.com.br

iD Bruna Silveira Chaves

Universidade Federal de Juiz de Fora, Juiz de Fora, Minas Gerais, Brasil profabrunachaves@gmail.com

Resumo: Esta pesquisa analisou como a interação entre as crianças de uma Creche e os significados de gênero que emergem de brinquedos e brincadeiras na infância contribuem para a construção de suas identidades de gênero. O estudo, de caráter qualitativo, utilizou a observação participante para analisar a interação entre 15 crianças de uma turma, com idades entre 3 e 4 anos, com as educadoras, os brinquedos e as brincadeiras. Percebeu-se que as experiências entre as crianças são atravessadas por discursos performativos de gênero. Evidenciou-se nas inte-

1 Pesquisa desenvolvida com apoio financeiro. (Bolsa de Monitoria/UFJF). 
rações que os papéis de gênero estão próximos daqueles vividos pelos adultos com os quais elas convivem e os brinquedos e brincadeiras tendem a reproduzir os papéis de masculinidade e feminilidade normativa. Palavras-chave: Identidade de gênero. Jogos e brincadeiras. Cultura infantil. Creche.

\begin{abstract}
This research analyzed how the interaction between children of a nursery, as well as the meanings of gender, which emerge from toys and games in childhood, contribute to the construction of their gender identities. As a qualitative study, it used participant observation to analyze the interaction between 15 children in a class, aged between 3 and 4 years, with the educators and with toys and games. It was noticed that the experiences among children are crossed by gender performance discourses. It was evident in the interactions that gender roles are close to those experienced by adults with whom they live and toys and games tend to reproduce the roles of normative masculinity and femininity.
\end{abstract}

Keywords: Gender identity. Games and pranks. Children's culture. Nursery.

Resumen: Esta investigación analizó cómo la interacción entre los niños de una guardería, así como los significados de género, que surgen de los juguetes y juegos en la infancia, contribuyen a la construcción de sus identidades de género. El estudio cualitativo utilizó la observación participante para analizar la interacción entre 15 niños de una clase, de entre 3 y 4 años, con los educadores y con juguetes y juegos. Se notó que las experiencias entre los niños están cruzadas por discursos de desempeño de género. Fue evidente en las interacciones que los roles de género son cercanos a los experimentados por los adultos con quienes viven y los juguetes y juegos tienden a reproducir los roles de masculinidad y feminidad normativas.

Palabras-clave: identidad de género. Juegos y juegos. Cultura infantil. Guardería.

Submetido em: 11-08-2020

Aceito em: 27-04-2021 


\section{Introdução}

O presente estudou motivou-se por alguns questionamentos referentes à relação gênero e infância, são eles: Como as crianças se relacionam com as questões de gênero e constroem suas identidades no cotidiano? Como o gênero e a educação subjetivam a formação das crianças desde as creches? Como as instituições e seus educadores contribuem para a formação dessas identidades? Como os momentos de interação entre as crianças durante as brincadeiras atuam nesse processo? Como os brinquedos, levando em conta seu valor simbólico, também participam da construção da identidade de gênero das crianças?

A infância é o momento em que a criança começa a se apropriar de imagens e de diversas representações sociais dadas culturalmente, advindas de diversas fontes. Uma dessas fontes são os brinquedos, uma vez que eles proporcionam para a criança "um suporte de ação, de manipulação, de conduta lúdica", trazendo, portanto, "formas e imagens, símbolos para serem manipulados" (BROUGÈRE, 2006, p. 40).

O conceito de criança adotado neste estudo parte da interligação entre seus aspectos sociais, culturais e históricos. Deve-se ressaltar a importância de considerar a diversidade da infância marcada principalmente pelas condições sociais em que vivem as crianças, pois, além de possuírem suas especificidades biopsicológicas, "distribuem-se pelos diversos modos de estratificação social: a classe social, a etnia a que pertencem, a raça, o gênero, a região do globo onde vivem" (SARMENTO, 2005, p. 370).

As crianças, enquanto atores sociais, também são construtoras de culturas. As culturas infantis podem ser compreendidas pela capacidade que as crianças possuem de construírem modos de significação do mundo e de ação intencional próprios, que diferem das formas dos adultos (SARMENTO, 2003). Esses modos de significação e ação, todavia, não nascem de forma espontânea. 
Construção das identidades de gênero na infância: os discursos dos brinquedos... karine Natalie Barra Godoy • Ludmila Mourão • Ayra Lovisi Oliveira • Bruna Silveira Chaves

Os elementos constitutivos das culturas lúdicas infantis são os jogos e as brincadeiras, os brinquedos, os rituais, os gestos e as palavras, e a interação da criança com as brincadeiras e com os brinquedos desencadeia nela a constituição do jogo simbólico ou do "faz-de-conta", que consiste na reprodução e recriação da realidade vivida a partir de seu imaginário (SARMENTO, 2003).

Assim, Kishimoto (2008) assevera que os brinquedos e as brincadeiras são importantes espaços para a construção do gênero e que, nesses processos de socialização e formação de identidade das crianças, podem ser construídas práticas de escolha de brinquedos e de brincadeiras por gênero, podendo criar estereótipos logo na infância.

No que tange às questões de gênero, formações de identidades e educação de crianças, Guizzo (2013) aponta que as instituições escolares estão profundamente implicadas no processo de construção das identidades infantis. Moreno (1999) considera que essas instituições possuem, além da função da formação intelectual, a função da formação social dos indivíduos, tendo em vista os padrões culturais adotados como a norma a ser seguida. As regulações e controles sofridos por meninas e meninos dentro das instituições educacionais são, na maioria das vezes, sutis; ocorrendo repetidas vezes e de diversas formas, sendo sustentados pelo argumento de que existe uma "essência" ou "natureza" determinante para explicar os comportamentos de ambos.

Entendemos o gênero a partir da concepção de Judith Butler (1990). Para a autora, o gênero é "a contínua estilização do corpo, um conjunto de atos repetidos no interior de um quadro regulatório altamente rígido e que se cristaliza ao longo do tempo para produzir a aparência de uma substância, a aparência de uma maneira natural de ser" (p. 33).

Quando se fala em "estilização do corpo", Butler refere-se à noção de inscrição corporal do gênero, ou seja, da exteriorização 
Construção das identidades de gênero na infância: os discursos dos brinquedos... karine Natalie Barra Godoy • Ludmila Mourão • Ayra Lovisi Oliveira • Bruna Silveira Chaves

e conservação dos discursos ${ }^{2}$ na superfície do corpo, através dos gestos e artefatos. A autora localiza o gênero no contexto dos discursos pelos quais é enquadrado e constituído, de maneira a evidenciar seu caráter construído em oposição ao natural. Isto é, o gênero é discursivamente construído (SALIH, 2015).

O gênero, enquanto efeito de um discurso que preexiste ao sujeito, é "constituinte da identidade que se pretende ser, ou que se simula ser" (BUTLER, 1990, p. 25). No que concerne às identidades de gênero e sua definição, Louro (1997, p. 28) afirma que:

\begin{abstract}
Em suas relações sociais, atravessadas por diferentes discursos, símbolos, representações e práticas, os sujeitos vão se construindo como masculinos ou femininos, arranjando e desarranjando seus lugares sociais, suas disposições, suas formas de ser e de estar no mundo. Essas construções e esses arranjos são sempre transitórios, transformando-se não apenas ao longo do tempo, historicamente, como também transformando-se na articulação com as histórias pessoais, as identidades sexuais, étnicas, de raça, de classe...
\end{abstract}

A partir do exposto, a presente pesquisa tem o objetivo de analisar como a interação entre as crianças da Creche Comunitária Sorriso de Criança ${ }^{3}$ e os significados de gênero que emergem de brinquedos e brincadeiras na infância contribuem para a construção de suas identidades de gênero.

O estudo se justifica pela possibilidade de evidenciar a criança enquanto ser ativo na sociedade e de compreendermos como as relações de gênero e a formação de identidades estão implicadas na cultura infantil e são desenvolvidas nos processos de socialização de crianças nas creches. Em meio a retrocessos no campo político, com o surgimento de propostas fundamentalistas - como as do projeto Escola Sem Partido, que se posiciona contra qualquer

2 Judith Butler utiliza o termo discurso a partir das formulações de Foucault, entendendo-o como um grande grupo de enunciados. Os enunciados são compreendidos por Foucault "como eventos reiteráveis que estão ligados por seus contextos históricos" (SALIH, 2015, p. 69).

3 Para garantirmos o anonimato, adotamos nomes fictícios tanto para a Creche Comunitária como para os(as) participantes da pesquisa. 
Construção das identidades de gênero na infância: os discursos dos brinquedos... karine Natalie Barra Godoy • Ludmila Mourão • Ayra Lovisi Oliveira • Bruna Silveira Chaves

tipo de abordagem no campo educacional sobre as questões que envolvem o gênero -, este estudo também se caracteriza como um ato de resistência. Tendo em vista que o gênero está presente em todos os espaços de interação social, devemos visibilizá-lo a fim de desconstruir naturalizações e possíveis interdições sofridas por meninos e meninas que contribuem para o processo de desigualdade e, por consequência, para a manutenção do status quo, ou seja, os padrões normativos de gênero impostos culturalmente pela sociedade.

Nesse sentido, o conceito de identidade desenvolvido por Stuart Hall (2014) corrobora esta pesquisa para compreendermos que as identidades estão constantemente em processo de mudança e transformação, não assinalando, portanto, "um núcleo estável do eu que passa, do início ao fim, sem qualquer mudança, por todas as vicissitudes da história" (p. 108). Dessa maneira, a formação das identidades das crianças acontece a partir das relações sociais, da linguagem e dos discursos, e vêm se constituindo ao longo da vida, desde a infância até a idade adulta.

No que tange às identidades de gênero, podemos caracterizá-las como performativas, pois entendemos que já nascemos em um contexto sociocultural com discursos generificados e generificantes, os quais produzem sujeitos que se identificam com o feminino e o masculino. Compreendemos também que não há identidade de gênero que anteceda a linguagem, uma vez que "a identidade é uma prática significante, e os sujeitos culturalmente inteligíveis são efeitos e não causas dos discursos" (BUTLER, 1990, p. 145).

Aproximando essas reflexões sobre identidades de gênero com a infância - foco deste estudo - pode-se dizer, segundo Bento (2006), que é nesse momento da vida que os enunciados performativos são interiorizados e se produz a estilização dos gêneros como, por exemplo: "Homem não chora" ou "Sente-se como uma menina". 
Construção das identidades de gênero na infância: os discursos dos brinquedos... karine Natalie Barra Godoy • Ludmila Mourão • Ayra Lovisi Oliveira • Bruna Silveira Chaves

É esse entendimento de identidade de gênero performativa que se inscreve no ser humano desde antes do seu nascimento através de constantes repetições de códigos culturais, que nos desafia a investigar como esse processo de construção das identidades de gênero se dá desde a mais tenra idade, associado ao contexto da Educação Infantil, em que estão entrelaçados o cuidar, o educar e a cultura infantil.

Entendendo que a brincadeira está inscrita em um sistema de significações da cultura infantil, deve-se considerá-la como algo construído social e culturalmente e não inato à criança, pelo menos no que diz respeito ao modo como ela adquire tal prática junto às pessoas. Portanto, "brincar não é uma dinâmica interna do indivíduo, mas uma atividade dotada de uma significação social precisa que, como outras, necessita de aprendizagem" (BROUGÈRE, 2002, p. 20).

Brougère (2006) também destaca que a socialização da criança, ou seja, o conjunto de processos pelos quais ela passa, que a permite assimilar códigos sociais e culturais para se comunicar com os outros membros da sociedade, se dá através de múltiplas interações. Os brinquedos e as brincadeiras fazem parte de um sistema de significação e representação social e, sendo assim, fazem com que a criança assimile códigos culturais através dos conteúdos simbólicos e imagens que são transmitidas a elas. Nesse sentido, pode-se afirmar que as concepções de gênero estão incluídas nessa assimilação e são pelas crianças representadas.

Ainda segundo Brougère (2006), em decorrência da tradição cultural são associadas à infância representações do masculino e do feminino, sendo os brinquedos e as brincadeiras importantes referenciais de gênero. Brougère (2004) aponta que desde a pré-escola os comportamentos lúdicos de meninas e meninos se diferenciam, e acrescenta que a "apresentação comercial dos brinquedos nas vitrines, prateleiras, catálogos, propagandas é amplamente estruturada a partir da diferença entre brinquedos de meninas e brinquedos de meninos" (p. 289). 
Construção das identidades de gênero na infância: os discursos dos brinquedos... karine Natalie Barra Godoy • Ludmila Mourão • Ayra Lovisi Oliveira • Bruna Silveira Chaves

Partindo da ideia de que a criança não só se apropria dos códigos culturais, mas também os ressignificam, podemos considerar que a brincadeira e o brinquedo não são apenas lugares de reprodução da cultura de gênero hegemônica, mas também abrem espaço para a sua construção e subversão.

\section{Métodos}

O presente estudo foi realizado na Creche Comunitária Sorriso de Criança, localizada na Zona Oeste de Juiz de Fora, que iniciou suas atividades em 1988 priorizando o atendimento às famílias em situação de vulnerabilidade e risco pessoal e social. Atualmente, atende crianças com idades entre 4 meses e 3 anos e 11 meses.

A pesquisa caracteriza-se como qualitativa, pois foi necessário imergir no campo de pesquisa, com a intenção de observar e registrar suas práticas, linguagens e hábitos, para compreender os sentidos e significados atribuídos às atividades desenvolvidas.

Participaram da pesquisa 15 crianças, que caracterizavam a "Turma de 3 anos", com idades entre 3 e 3 anos e 11 meses (7 meninos e 8 meninas). A participação das crianças foi autorizada pelos seus responsáveis através da assinatura do Termo de Consentimento Livre e Esclarecido (TCLE).

O delineamento do estudo se deu através da observação participante, técnica em que o pesquisador se encontra em contato com os processos e dinâmicas culturais nos quais o ambiente e os colaboradores da pesquisa estão imersos (ANDRÉ, 1995). Dessa forma, o cotidiano da turma de 3 anos foi acompanhado durante quatro meses: de agosto a novembro de 2016, em dias alternados (segunda, quarta e sexta-feira). As observações foram registradas em um diário de campo. 


\section{Resultados e discussão}

A partir dos registros no diário de campo, as análises foram subdividas nas seguintes temáticas: brinquedos e brincadeiras na creche - entre repetições, reafirmações e ressignificações, que retratou de maneira geral os brinquedos utilizados e as brincadeiras realizadas no espaço externo e dentro de sala; "Eu tô faxinando e tô muito ocupada" - performatizando o gênero a partir dos cantinhos temáticos, que traz, mais especificamente, os cantinhos temáticos da casinha, fazendinha, beleza e dos carrinhos como espaços onde se estabelecem as relações de gênero.

\subsection{Brinquedos e brincadeiras na creche: entre repetições, reafirmações e ressignificações}

As opções de brinquedos que as crianças tinham para explorar, na creche, eram frequentemente as mesmas: bonecas, carrinhos, motos, caminhões, ferrinho de passar roupa, bolsas, dentre outros que eram menos explorados por elas. No parquinho, os brinquedos disponíveis eram específicos para brincar na areia, como potes e peneirinhas, além de carrinhos, caminhões, bonecas, panelinhas, pratinhos, copos e algumas ferramentas.

O fato de os brinquedos da creche girarem em torno desses citados acima, sendo, portanto, disponibilizado um tipo de brinquedo em detrimento do outro, implica diretamente nas escolhas das crianças. Walter Benjamin (2009, p. 96) afirma que a escolha de brinquedos pelas crianças está diretamente ligada às influências dos adultos:

[...] o mundo da percepção infantil está impregnado em toda parte pelos vestígios da geração mais velha [...]. Pois quem senão o adulto fornece primeiramente à criança os seus brinquedos? E embora reste a ela uma certa liberdade em aceitar ou re- 
Construção das identidades de gênero na infância: os discursos dos brinquedos... karine Natalie Barra Godoy • Ludmila Mourão • Ayra Lovisi Oliveira • Bruna Silveira Chaves

cusar as coisas, não poucos dos mais antigos brinquedos (bola, arco, pipa) terão sido de certa forma impostos à criança como objetos de culto, os quais só mais tarde, e certamente graças à força da imaginação infantil, transformaram-se em brinquedos.

Logo, é fundamental pensar as ações e o modo como essas crianças se expressam diante das situações como parte de um complexo conjunto de forças, em que a creche como um todo (diretrizes que regem a instituição, a organização, as educadoras, os brinquedos disponíveis, dentre outros) tem extrema relevância na formação desses meninos e meninas. A ideia que gostaríamos de tratar é que a presença ou ausência de brinquedos no espaço escolar é decorrente de uma concepção de jogo e de sua utilidade/ necessidade atribuída pelo educador para a educação da criança pequena.

De modo geral, foi possível notar que as brincadeiras mais comuns realizadas pelas meninas foram aquelas que retratavam o cotidiano familiar, como "mamãe e filhinha", tanto enquanto ocupavam o espaço da sala quanto nos momentos em que estavam no parquinho. Já os meninos optavam por brincadeiras com carrinhos (ou outros brinquedos que simbolizassem o ato de dirigir) e aquelas consideradas mais ativas e agressivas, como correr, escorregar e como a "lutinha".

Foi possível observar que tanto a menina quanto o menino apresentaram discursos que as associam ao ser mulher/mãe, tarefas domésticas e cuidados com os filhos(as). As situações protagonizadas pela menina e pelo menino se apresentam a seguir, respectivamente:

Estou próxima das meninas e Aura quer brincar comigo de mamãe e filhinha. Ela diz: "Meu nome era cozinheira". Para tentar compreender melhor o que ela quis dizer, eu perguntei: “Era?" e ela respondeu: “Era, porque eu sou sua mãe" (DIÁRIO DE CAMPO, 2016). 
Construção das identidades de gênero na infância: os discursos dos brinquedos... karine Natalie Barra Godoy • Ludmila Mourão • Ayra Lovisi Oliveira • Bruna Silveira Chaves

\begin{abstract}
Henrique quando passou perto das meninas, parou e chamou Marcela de mãe pedindo para ela fazer comida para ele. Marcela, então brinca que está fazendo sua comida. Depois de um tempo, Henrique retorna e ela dá a comida a ele. Quando Henrique "termina de comer" ele sai e vai brincar novamente com os meninos (DIÁRIO DE CAMPO, 2016).
\end{abstract}

Em ambas as situações, pode-se observar que somente as meninas se identificam e se apropriam desse lugar de responsáveis pelas tarefas domésticas e cuidados com os(as) filhos(as), enquanto o menino não se reconhece desempenhando esse tipo de papel. As brincadeiras de faz de conta são a representação e recriação da realidade vivida a partir do imaginário da criança. Logo, é provável que o desempenho dos papéis de gênero representado pelas crianças tenha origem em seu cotidiano familiar.

Em relação às brincadeiras realizadas entre os meninos, as mais frequentes quando estão dentro de sala são as de carrinho e aquelas que fazem alusão à arma e à lutinha. E, quando estão no parquinho, são as brincadeiras de correr e escorregar.

Em relação aos brinquedos, nota-se que os meninos ressignificaram seu uso - o relógio assume a forma de volante e o ferrinho de passar se transforma em arma - e fizeram alusão a elementos que estão culturalmente associados à masculinidade.

Diante dessas situações e análises, percebe-se que os discursos presentes em nossas escolas e creches apontam que a construção das identidades se dá também a partir das experiências adquiridas no cotidiano. Além disso, a interação é tida como um importante fator de aprendizagem que se realiza no grupo social, devendo ser estimulada em todos os aspectos possíveis. Entretanto, observa-se, de acordo com Brougére (2006), que os brinquedos que se encontram nessas instituições para as crianças estão, na maioria das vezes, reiterando o mundo dos adultos, reforçando um universo normatizado de papéis sociais de gênero. 
Construção das identidades de gênero na infância: os discursos dos brinquedos... karine Natalie Barra Godoy • Ludmila Mourão • Ayra Lovisi Oliveira • Bruna Silveira Chaves

Em outra situação observada, a turma estava sob a responsabilidade de outra educadora e ela resolveu espalhar pela sala os brinquedos referentes ao cantinho da casinha. Havia, portanto, panelinhas, pia, fogão e algumas ferramentas.

Nessa situação, os meninos também ressignificaram os brinquedos dando uma conotação mais ativa e agressiva, simulando embate entre eles. Interessante observar que os meninos vão incluindo outros meninos na brincadeira. Silva acrescenta:

\begin{abstract}
A afirmação da identidade e a marcação da diferença implicam, sempre, as operações de incluir e de excluir. Dizer o que somos significa também dizer o que não somos. Afirmar a identidade significa demarcar fronteiras, significa fazer distinções entre o que fica dentro e o que fica fora. A identidade está sempre ligada a uma forte separação entre "nós" e "eles". Essa demarcação de fronteiras, essa separação e distinção, supõem e, ao mesmo tempo, afirmam e reafirmam relações de poder (SILVA, 2014, p. 82).
\end{abstract}

Em relação à interação entre meninos e meninas nas brincadeiras, verificou-se uma separação entre ambos os grupos, havendo situações de exclusão de algum menino pelas meninas. A educadora relata que "sempre que dá, eu tento interagir ali, mais nas brincadeiras dirigidas, porque nas que são livres, eu tento mesmo deixar mais livre" (Diário de campo).

Um aspecto relevante na interação entre meninas e meninos, e na mudança de comportamento das meninas na brincadeira, se deu a partir da alteração na dinâmica da utilização dos espaços. Foi observado que todas as vezes que era utilizado o espaço externo gramado, meninos e meninas eram estimulados a explorar o local subindo e descendo os aclives e declives de maneira ativa, havendo interação entre todos. Esse estímulo também foi observado quando o parquinho era utilizado sob a regra de não utilizarem os brinquedos do cesto (que continha panelinha, potes, peneirinha, bonecas), ocorrendo, assim, maior exploração do balanço e 
Construção das identidades de gênero na infância: os discursos dos brinquedos... karine Natalie Barra Godoy • Ludmila Mourão • Ayra Lovisi Oliveira • Bruna Silveira Chaves

principalmente do escorregador, em que as crianças simulavam situações de perigo e de aventura.

Apesar de haver mudança no comportamento das meninas, se tornando mais ativas, podemos observar que elas assumem o papel de meninas indefesas e frágeis que precisam ser salvas por um super-herói representado pela figura masculina, que expressa força e coragem.

Essa configuração de papéis é comumente vista em filmes e desenhos voltados para o público infantil. Na pesquisa realizada por Esperança e Dias (2010), com 24 crianças com idades entre 7 e 9 anos, foi verificado o grande interesse dos meninos pela violência de faz de conta em suas brincadeiras. Observou-se que esse interesse estava relacionado às performances das personagens oriundas de desenhos animados veiculados nas mídias, aos efeitos ficcionais de raios, robôs e de monstros sobrenaturais, e às trilhas sonoras que tornavam atrativas a disputa entre heróis e vilões.

A brincadeira, enquanto espaço de socialização e interação entre as crianças (por meio ou não dos brinquedos), pode ser considerada um importante instrumento no processo de construção das identidades de gênero das crianças. Nesse sentido, o gênero, entendido como código cultural, foi interpretado e apropriado pela criança, culminando na sua reprodução e performatização na brincadeira. A interação entre as crianças nesses momentos de brincadeira é potente para a construção das identidades de gênero entre os pares, na medida em que a identidade é construída a partir da relação com o outro.

\section{2 "Eu tô faxinando e tô muito ocupada": performatizando o gênero a partir dos cantinhos temáticos}

Os cantinhos temáticos eram organizados pela educadora dentro de sala de modo a deixar as crianças livres para escolherem em qual cantinho brincar. O objetivo desses cantinhos, segundo o 
Construção das identidades de gênero na infância: os discursos dos brinquedos... karine Natalie Barra Godoy • Ludmila Mourão • Ayra Lovisi Oliveira • Bruna Silveira Chaves

Projeto Político Pedagógico, é promover atividades diversificadas ao mesmo tempo, estimulando a autonomia da criança para escoIher onde estar e o que fazer.

Os cantinhos eram: "casinha", onde ficavam disponíveis bonecas, panelinhas, fogão, pia, geladeira, carrinho de bebê e banheira; "a fazendinha", na qual estavam disponíveis diversos animaizinhos de brinquedo; "carrinho", onde estavam disponíveis vários carrinhos e uma pista e, por fim, "beleza", em que eram disponibilizadas maquiagens (sombra, batom, blush), esmaltes, escova de cabelo, secador e prancha de alisar, tudo de brinquedo. Nem sempre todos os cantinhos eram montados no mesmo dia.

Uma das situações que chamou atenção ocorreu no cantinho da casinha. Observamos que a educadora havia organizado apenas esse cantinho. Nesse dia, a turma tinha apenas meninas presentes. Perguntamos para a educadora sobre a estruturação do cantinho e ela respondeu: “Como só tinha menina, eu montei só o cantinho da casinha. Pensei em fazer uma pintura, mas aí montei o cantinho... deixa elas brincarem um pouquinho" (Diário de campo). É possível notarmos que o discurso da educadora faz uma associação direta entre ser menina e brincar no cantinho da casinha. Essa situação nos remete à ideia de que as meninas ainda devem ser educadas para ocupar o espaço privado/doméstico. A chamada "divisão sexual do trabalho" é uma forma de organização típica da sociedade brasileira e mantida, nesse caso, pela creche. De acordo com essa divisão, os meninos devem ser prioritariamente preparados para a inserção na esfera produtiva e as mulheres na esfera reprodutiva e do cuidado.

Foi possível perceber, a partir dos discursos das educadoras, o quão enraizados estão em nossa sociedade os papéis de gênero, pois elas continuam reproduzindo o status quo na sua prática educacional.

Ainda que os papéis de gênero tradicionais - comportamentos, atitudes e modos de pensar que associam a mulher a casa e o homem ao espaço público - estejam se alterando, a mudança é 
Construção das identidades de gênero na infância: os discursos dos brinquedos... karine Natalie Barra Godoy • Ludmila Mourão • Ayra Lovisi Oliveira • Bruna Silveira Chaves

lenta, pois envolve padrões reproduzidos ao longo de várias gerações. Não apenas a família, onde começamos a incorporar esses papéis, mas também a escola, as creches, as empresas, a mídia e as demais instituições sociais contribuem para que esses padrões tradicionais sejam mantidos e performatizados. Assim, as pessoas em geral acreditam que esses padrões sejam determinados pela natureza e imutáveis, ou seja, que são decorrentes de nossos atributos biológicos. O reconhecimento de que os papéis de gênero são construções sociais, performativas e que variam entre culturas e ao longo do tempo é fundamental para a desconstrução dos discursos e práticas sociais normatizadoras.

Segundo a educadora, um dos seus objetivos com a atividade dos cantinhos temáticos é observar como a criança desenvolve sua autonomia para escolher do que brincar e como brincar. Porém, além de observar e identificar os comportamentos das crianças, acreditamos que seja necessário fomentar a reflexão delas sobre suas próprias ações que performatizam o gênero podendo limitar suas próprias experiências e a ação das outras crianças.

Nas observações foi possível perceber a ressignificação dos brinquedos pelas crianças de acordo com o gênero: os meninos preencheram a banheira - que é um brinquedo originário do cantinho da casinha com o valor simbólico associado a dar banho na boneca/bebê - com vários carrinhos, como se estes marcassem e autorizassem seu uso pelos meninos; já as meninas ressignificaram a pista de carrinhos no momento em que a utilizaram como cobertor; e uma criança ressignificou a geladeira, transformando-a em um carro. Dessa forma, fez com que esse artefato da cozinha, pertencente ao cantinho da casinha, adquirisse o valor simbólico de um carrinho, brinquedo culturalmente atribuído ao gênero masculino.

Essas situações vão ao encontro do pensamento de Brougère (2006), em que, na maioria das vezes, a criança, durante a brincadeira, registra e manipula as imagens e representações simbólicas presentes nos brinquedos, podendo transformá-las e dando a elas novas significações. No caso analisado, as crianças ressignificaram 
Construção das identidades de gênero na infância: os discursos dos brinquedos... karine Natalie Barra Godoy • Ludmila Mourão • Ayra Lovisi Oliveira • Bruna Silveira Chaves

os brinquedos e as brincadeiras, demarcando o cantinho da casinha como lugar próprio das meninas e o cantinho do carrinho, dos meninos.

Alguns estudos também observaram comportamentos em que as crianças se reorganizaram e transgrediram os padrões esperados. Na pesquisa de Teixeira (2001), realizada com meninas e meninos de 3 a 5 anos de idade, cujo objetivo centrou-se na compreensão da intermediação representada pela Educação Infantil e suas implicações na formação das identidades de gênero das crianças, foram encontrados resultados interessantes no que se refere aos atos que subverteram a organização habitual das brincadeiras. A tese de Finco (2010), cujo objetivo foi interpretar as interações entre as professoras e, principalmente, entre as crianças que transgrediam os padrões de gênero, apontou que, apesar das formas de controle e da Instituição de Educação Infantil pesquisada ter no sexo um importante critério para a organização e uso dos tempos e dos espaços, o poder das professoras sobre meninas e meninos não é universal e unilateral, indicando que o processo de socialização não se dá de forma passiva.

A partir do exposto, podemos afirmar que os brinquedos e as brincadeiras, enquanto artefatos culturais e representações sociais, permitem que as crianças assimilem os códigos presentes em nossa sociedade e cultura. Podemos considerá-los - os brinquedos e brincadeiras - importantes instrumentos de construção das concepções de mundo para as crianças, incluindo as concepções de gênero, que são por elas representadas nesses momentos lúdicos.

\section{Considerações finais}

Sobre a análise da interação entre as crianças da Creche Comunitária, os significados de gênero que emergem dos brinquedos e brincadeiras que contribuem para a construção de suas 
Construção das identidades de gênero na infância: os discursos dos brinquedos... karine Natalie Barra Godoy • Ludmila Mourão • Ayra Lovisi Oliveira • Bruna Silveira Chaves

identidades de gênero, encontramos que eles (brinquedos e brincadeiras) estão inseridos em um contexto cultural e formativo das crianças marcado pelo binarismo de gênero. Os sentidos atribuídos ao masculino e ao feminino foram performativamente demarcados a partir desses artefatos culturais que estão impregnados de valores simbólicos e códigos sociais normatizados.

Foi possível perceber também que as experiências entre as crianças são atravessadas por discursos que performatizam os gêneros. Evidenciou-se nas interações que, mesmo entre as crianças de pouca idade, os papéis de gênero estão muito próximos daqueles vividos pelos adultos com os quais convivem no mesmo contexto social, cultural e de cuidados, como a creche. E que os brinquedos e as brincadeiras tendem a reproduzir os papéis de masculinidade e feminilidade normativa, experimentadas em diferentes espaços de interação entre as crianças, e entre as crianças e os adultos, tanto da família quanto da Creche Comunitária.

Considerando que o processo de construção de identidade se dá na relação das pessoas com meio sociocultural, podemos dizer que a Instituição pesquisada e a educadora possuem papel importante na construção das identidades de gênero das crianças da turma investigada. Isso se deve ao fato de a Creche apresentar um discurso institucional de formação humana que orienta a prática pedagógica. Embora a educadora questione o binarismo de gênero e seus significados diante da sociedade, na maioria das vezes o reproduz, discursivamente, através da organização dos cantinhos e da distribuição de brinquedos, contribuindo para a construção de uma identidade pautada nas normas de gênero. Verificou-se também a forte influência da família nesse processo de formação, pois foram observados falas e gestos típicos do cotidiano familiar, os quais foram performatizados pelas crianças durante as brincadeiras.

Os brinquedos disponíveis e a frequência de sua utilização foram fundamentais para que, de alguma forma, determinassem o modo como as crianças brincavam. Percebe-se, portanto, que a força cultural do binarismo de gênero reside justamente em sua 
Construção das identidades de gênero na infância: os discursos dos brinquedos... karine Natalie Barra Godoy • Ludmila Mourão • Ayra Lovisi Oliveira • Bruna Silveira Chaves

repetição e reiteração. Entretanto, como exposto, tais processos não se repetem de forma idêntica.

Enfim, além de o espaço da Creche Comunitária ter demonstrado ser importante na formação identitária de meninos e meninas, podemos dizer também que as interações entre as crianças e suas experiências lúdicas através do brincar e do brinquedo assumem lugar significativo na construção da sua própria identidade de gênero e dos seus pares, uma vez que suas identidades vão se formando em relação ao outro, à percepção das diferenças e dos códigos presentes na cultura.

A partir do que foi observado e analisado, emerge a necessidade de mais estudos que possam desvelar outros contextos culturais e expor a complexidade das relações de gênero presentes em contextos educacionais, especialmente os infantis.

\section{Referências}

ANDRÉ, M. E. D. A. de. Etnografia da prática escolar. Campinas: Papirus, 1995.

BENJAMIN, W. Reflexões sobre a criança, o brinquedo e a educação. 2. ed. São Paulo: Editora 34, 2009.

BENTO, B. A reinvenção do corpo: sexualidade e gênero na experiência transexual. Rio de Janeiro: Garamound, 2006.

BROUGÈRE, G. A criança e a cultura lúdica. In: KISHIMOTO, Tizuko Morchida (Org.). 0 brincar e suas teorias. São Paulo: Pioneira Thomson Learning, 2002.

BROUGÈRE, G. Brinquedo e companhia. 5. ed. São Paulo: Cortez, 2004.

BROUGÈRE, G. Brinquedo e cultura. 3. ed. São Paulo: Cortez, 2006.

BUTLER, J. Problemas de gênero: feminismo e subversão da identidade. Rio de Janeiro: Civilização brasileira,1990. 
ESPERANÇA, J. A.; DIAS, C. S. Meninos versus meninas: representações de gênero em desenhos animados e seriados televisivos sob olhares infantis. Educação. Santa Maria, v. 35, n. 3, p. 533546, set./dez. 2010.

FINCO, D. Educação infantil, espaços de confronto e convívio com as diferenças: análise das interações entre professoras e meninas e meninos que transgridem as fronteiras de gênero. 2010. Tese (Doutorado em Educação) - Faculdade de Educação, Universidade de São Paulo, São Paulo, 2010.

GUIZZO, B. S. Masculinidades e feminilidades em construção na Educação Infantil. In: FELIPE, J.; GUIZZO, B. S.; BECK, D. Q. (Org.). Infâncias, gênero e sexualidade: nas tramas da cultura e da educação. Canoas: Ed. Ulbra, 2013.

HALL, S. Quem precisa de identidade? In: SILVA, Tomaz Tadeu da (Org.). Identidade e diferença: A perspectiva dos Estudos Culturais. 15. ed. Petrópolis: Vozes, 2014.

KISHIMOTO, T. M.; ONO, A T. Brinquedo, gênero e educação na brinquedoteca. Pro-Posições, v. 19, n. 3, p. 209-233, set./dez. 2008.

LOURO, G. L. Gênero, sexualidade e educação: uma perspectiva pós-estruturalista. 6. ed. Petrópolis: Vozes, 1997.

MORENO, M. Como se ensinar a ser menina: o sexismo na escola. São Paulo: Moderna, 1999.

SALIH, S. Judith Butler e a teoria queer. Belo Horizonte: Autêntica, 2015.

SARMENTO, M. J. Imaginário e culturas da infância. Cadernos de Educação, Pelotas, v. 12, n. 21, p. 51-69, 2003.

SARMENTO, M. J. Gerações e alteridade: interrogações a partir da sociologia da infância. Educação \& Sociedade, Campinas, v. 26, n. 91, p. 361-378, maio/ago. 2005.

SILVA, T. T. da. A produção social da identidade e diferença. In: SILVA, Tomaz Tadeu da (Org.). Identidade e diferença: A perspectiva dos Estudos Culturais. 15. ed. Petrópolis: Vozes, 2014. 
Construção das identidades de gênero na infância: os discursos dos brinquedos... karine Natalie Barra Godoy • Ludmila Mourão • Ayra Lovisi Oliveira • Bruna Silveira Chaves

TEIXEIRA, F. B. Meninas e meninos na escola: uma aquarela de possibilidades. 2001. Dissertação (Mestrado em Educação) Centro de Ciências Humanas e Artes, Universidade Federal de Uberlândia, Uberlândia, 2001.

\section{Publisher}

Universidade Federal de Goiás. Faculdade de Educação Física e Dança. Publicação no Portal de Periódicos UFG. As ideias expressadas neste artigo são de responsabilidade de seus autores, não representando, necessariamente, a opinião dos editores ou da universidade. 